\title{
Intermethod Comparison and Evaluation of Measured Near Surface Residual Stress in Milled Aluminum
}

\author{
C. R. Chighizola' ${ }^{1}$ C. R. D'Elia ${ }^{1}$ - D. Weber ${ }^{2} \cdot$ B. Kirsch ${ }^{2} \cdot$ J. C. Aurich ${ }^{2} \cdot$ B. S. Linke ${ }^{1}$ M. R. Hill ${ }^{1}$
}

Received: 20 April 2020 / Accepted: 12 May 2021 / Published online: 17 June 2021

(c) The Author(s) 2021

\begin{abstract}
Background While near surface residual stress (NSRS) from milling is a driver for distortion in aluminum parts there are few studies that directly compare available techniques for NSRS measurement.

Objective We report application and assessment of four different techniques for evaluating residual stress versus depth in milled aluminum parts.

Methods The four techniques are: hole-drilling, slotting, $\cos (\alpha)$ x-ray diffraction $(\mathrm{XRD})$, and $\sin ^{2}(\psi) \mathrm{XRD}$, all including incremental material removal to produce a stress versus depth profile. The milled aluminum parts are cut from stress-relieved plate, AA7050-T7451, with a range of table and tool speeds used to mill a large flat surface in several samples. NSRS measurements are made at specified locations on each sample.

Results Resulting data show that NSRS from three techniques are in general agreement: hole-drilling, slotting, and $\sin ^{2}(\psi)$ XRD. At shallow depths $(<0.03 \mathrm{~mm}), \sin ^{2}(\psi)$ XRD data have the best repeatability $(<15 \mathrm{MPa})$, but at larger depths $(>0.04 \mathrm{~mm}$ ) hole-drilling and slotting have the best repeatability $(<10 \mathrm{MPa})$. NSRS data from $\cos (\alpha)$ XRD differ from data provided by other techniques and the data are less repeatable. NSRS data for different milling parameters show that the depth of NSRS increases with feed per tooth and is unaffected by cutting speed.

Conclusion Hole-drilling, slotting, and $\sin ^{2}(\psi)$ XRD provided comparable results when assessing milling-induced near surface residual stress in aluminum. Combining a simple distortion test, comprising removal of a $1 \mathrm{~mm}$ thick wafer at the milled surface, with a companion stress analysis showed that NSRS data from hole-drilling are most consistent with millinginduced distortion.
\end{abstract}

Keywords Residual stress measurement $\cdot$ Machining $\cdot$ Milling $\cdot$ Slotting $\cdot$ Hole-drilling $\cdot$ X-ray diffraction

\section{Introduction}

Near surface residual stress (NSRS) in machined samples likely contributes to in situ and post process distortion. To understand it as a driving factor for distortion, it has to be measured and characterized. Machining distortion is defined as the deviation of a part shape from its intended geometry after being released from restraining fixtures [1]. Distortion

M. R. Hill

mrhill@ucdavis.edu

1 Department of Mechanical and Aerospace Engineering, University of California, One Shields Avenue, Davis, CA 95616, USA

2 Institute for Manufacturing Technology and Production Systems, TU Kaiserslautern, Erwin-Schrödinger-Straße 52, 67663 Kaiserslautern, Germany is driven by the residual stress due to prior material processing and induced by the machining process. Understanding how the residual stress drives distortion is particularly critical for large thin-walled components such as those often found in the aerospace industry, which experiences significant losses from machining distortion [2, 3]. Large, thinwalled aerospace components most often have tight dimensional tolerances and low stiffness, leaving them prone to problems arising from machining stresses.

Distortion and NSRS are impacted by the machining parameters. Prior work has shown that machining parameters such as cutting speed, feed per tooth, and the resulting machining forces correlate with part distortion. Masoudi, et.al., observed that the distortion potential of thin parts increases almost linearly with increasing cutting force using a combination of cutting speeds and feed rates [4]. The study also showed that there was a systematic increase 
of compressive near surface residual stress with larger cutting forces. Another study by $\mathrm{Li}$ et al. investigated the effect of machining depth of cut on thin walled aluminum and the resulting NSRS and distortion [5]. They found that decreasing depth of cut reduced compressive NSRS. The above observations are part of a group of studies performed by various authors, all of which investigate the influence of machining parameters on NSRS. However, most of these studies collect NSRS data using a single measurement technique.

There is a lack of studies that measure the near surface residual stresses of machined samples with multiple techniques. The focus of this study is to investigate four techniques for measuring NSRS. These are hole-drilling, slotting, and two different types of $\mathrm{x}$-ray diffraction (XRD): $\cos (\alpha)$ and $\sin ^{2}(\psi)$. All four techniques involve the incremental removal of material at the surface with measurements taken at each increment. This results in a profile of measured NSRS as a function of depth position from the surface. The precision of the measurement techniques depends on the sample material, sample surface finish, technique used, and operator experience. Studies performed at the National Physical Laboratory (NPL), UK address several methodological aspects of these residual stress measurement techniques including repeatability experiments for hole-drilling and $\sin ^{2}(\psi)$ XRD techniques [6]. This study will apply the four techniques described above consistently to machined aluminum samples.

A repeatability experiment will quantify precision of the four NSRS techniques, which is the first objective of this study. A typical repeatability experiment performs a single measurement on multiple samples with similar properties and reports the mean and repeatability standard deviation using standard formulae [7]. Here, we make multiple measurements in a single sample with a uniform near-surface stress field, as in [8], measuring NSRS at multiple locations on a uniformly machined plate.

The second objective is to determine whether some techniques may be advantageous for measuring NSRS in milled aluminum. This will be achieved by evaluating the mean values of stress versus depth for each technique, comparing measurement results side-by-side, and assessing potential for bias among techniques. Comparing standard deviations of each technique helps assess their precision. Thus, repeating the repeatability experiment for multiple techniques provides an intermethod comparison of the measurement techniques.

A typical profile of NSRS imparted by milling often follows a root shape $(-\sqrt{ }-)$ [9]. The minimum of this $\sqrt{ }$-shaped curve is defined as the maximum compressive stress, which occurs at a specific depth. Generally, for deep depths the $\sqrt{ }$-shaped curve returns to near zero stress in a workpiece initially free of residual stress. Several researchers have identified a clear trend of increasing depth of maximum compressive stress with increasing feed per tooth. Denkena, et al. observed that an increase in feed per tooth systematically leads to more compressive stress parallel to the feed direction when milling $35 \mathrm{~mm}$ thick Al7449-T7651 blocks with cemented carbide end mills and indexable tools [10, 11]. For example, Denkena, et al. found a maximum compressive stress of $-400 \mathrm{MPa}$ at a depth of $45 \mu \mathrm{m}$ with a trend back to $0 \mathrm{MPa}$ at depths greater than $200 \mu \mathrm{m}$ for a feed per tooth of $0.35 \mathrm{~mm}$. Rao, et al. found a similar trend in Al7050-T6 when milling with uncoated carbide and diamond inserts [12]: at a feed per tooth of $0.38 \mathrm{~mm}$ they found the maximum compressive stress occurred $40 \mu \mathrm{m}$ beneath the milled surface; however, Rao, et al. did not observe a trend back to zero stress at deep depths. Tang, et al. [13] could not observe a systematic trend of maximum compressive stress parallel or perpendicular to the feed direction when milling Al7050-T7451 with TiB2-coated end mills. They did find that for a feed per tooth of $0.2 \mathrm{~mm}$, the maximum compressive stress occurred between 15 and $25 \mu \mathrm{m}$ and trended to $0 \mathrm{MPa}$ at depths greater than $50 \mu \mathrm{m}$. In these studies, the residual stress at the surface tended to become less compressive, or even tensile, with increasing feed per tooth $[10,14]$.

Cutting speed is another machining parameter that may influence NSRS. Several studies observed different effects of cutting speed on NSRS. Denkena, et al. [11] stated that the cutting speed influences neither the maximum compressive residual stress nor the depth where it occurs. However, other studies by the same authors showed that different tools and cutting speeds led to an increase in maximum compressive stress with increased cutting speed [10]. Contrary results were observed by Tang, et al. [13] and Rao, et al. [12] who found increased cutting speed resulted in decreased compressive stress and decreased depth of residual stress. Other machining parameters, such as cutting depth and width, may also affect the NSRS state but are not considered herein. All of the data supporting these prior works were collected using the $\sin ^{2}(\psi)$ XRD technique.

In summary, different machining parameters may cause different NSRS states including differences in the magnitude and depth of the residual stresses. Therefore, the third objective of this work is to assess NSRS of aluminum samples that are milled with a range of milling parameters resulting in different loads and intended to produce a range of stress conditions. This objective is performed as exploratory work with only a few measurements and provides a basis for future study.

The literature makes the connection between distortion in thin parts and machining parameters. For increasing feed per tooth and cutting speed the potential for and magnitude of distortion increases [4]. The bulk of the work above relates distortion to NSRS. Therefore, the fourth objective of this work is to connect the measured NSRS to distortion quantitatively using a simple experiment and a companion model. 
Future work is planned that will use both the experiment and companion model to further detail the connection between measured NSRS and distortion.

\section{Methods}

\section{Sample Description}

A set of several aluminum samples were cut from a single piece of $102 \mathrm{~mm}$ thick AA7050-T7451 plate stock. Samples, with dimensions of $206 \mathrm{~mm}$ by $102 \mathrm{~mm}$ by $28 \mathrm{~mm}$, were saw cut with the $206 \mathrm{~mm}$ dimension along the longitudinal plate rolling direction, the $28 \mathrm{~mm}$ dimension along the long transverse, and the $102 \mathrm{~mm}$ dimension along the short transverse. The samples were milled on one of the $206 \mathrm{~mm}$ by $102 \mathrm{~mm}$ faces, with each sample milled with a specific set of milling parameters. A coordinate frame is defined relative to the sample dimensions, with $\mathrm{x}$ along the $206 \mathrm{~mm}$ length, $\mathrm{y}$ along the $102 \mathrm{~mm}$ width, and $\mathrm{z}$ directed into the machined surface.

\section{Machining Description}

\section{Clamping and Tool Selection}

The samples were centered and clamped in a conventional $125 \mathrm{~mm}$ milling vise, with the $125 \mathrm{~mm}$ vise jaw along the $206 \mathrm{~mm}$ length. The $206 \mathrm{~mm}$ length was aligned with the $\mathrm{x}$ direction of the machining center, the $102 \mathrm{~mm}$ length aligned with the y direction, and the $28 \mathrm{~mm}$ length aligned with the $\mathrm{z}$ direction. Approximately $5.5 \mathrm{~mm}$ of the $28 \mathrm{~mm}$ length of the sample was exposed above the vise jaw. The Kennametal F3AA1200AWL cemented-carbide end mill was chosen as it represents a typical end mill used in highspeed machining of aerospace grade aluminum alloys. The $12 \mathrm{~mm}$ end mill has 3 flutes, $\mathrm{a} 45^{\circ}$ helix angle, and zero corner radius. The samples were machined in a DMG Mori DMU $70 \mathrm{CNC}$ milling machine by climb milling along the $206 \mathrm{~mm}$ length. The depth of cut $a_{e}$ and the width of cut $a_{p}$ were held constant at 3 and $4 \mathrm{~mm}$, respectively. Table 1 shows sample identifiers and the combinations of cutting speed $\left(\mathrm{v}_{\mathrm{c}}\right)$ and feed per tooth $\left(\mathrm{f}_{\mathrm{z}}\right)$ used in milling. The material removal rate $\left(\mathrm{Q}_{\mathrm{w}}\right)$ shown in the table is computed from the width of cut, depth of cut, and feed rate $\left(\mathrm{v}_{\mathrm{f}}\right)$ using $\mathrm{Q}_{\mathrm{w}}=\left(\mathrm{a}_{\mathrm{e}}\right)\left(\mathrm{a}_{\mathrm{p}}\right)\left(\mathrm{v}_{\mathrm{f}}\right)$ [15]. The average chip thickness $\left(\mathrm{h}_{\mathrm{m}}\right)$ is computed from $\mathrm{a}_{\mathrm{e}}$ and the tool diameter (d) using $\mathrm{h}_{\mathrm{m}}=\mathrm{f}_{\mathrm{z}} \mathrm{x} \operatorname{sqrt}\left(\mathrm{a}_{\mathrm{e}} / \mathrm{d}\right)$. The machining parameter sets are referred to as modes with mode 1,2, and 3 sharing the same cutting speed and varying in feed per tooth. Mode 3 represents a roughing process with the highest load due to the highest feed per tooth. Mode 4 and mode 1 share the same feed per tooth but vary in cutting speed.

\section{Sample Topography}

Two types of surface data were generated to investigate the topographical differences in the milled surfaces. These data were three dimensional (3D) optical surface scans and surface roughness traces generated out of the 3D optical surface scans. Roughness traces were extracted perpendicular to the feed direction (along the $102 \mathrm{~mm}$ sample direction) with a cut-off length of $2.5 \mathrm{~mm}$. A NanoFocus $\mu$ surf Explorer with the optical module $1600 \mathrm{~S}(10 \times$ magnification, numerical aperture 0.3 ) was used to generate the 3D surface scans.

\section{Residual Stress Measurements}

\section{Depth Profiling}

The literature shows that the stresses of interest lie near the machined surface. Work done by Tang et al. showed residual stress in milled 7050-T7451 had maximum compressive stress at depths of 0.015 to $0.020 \mathrm{~mm}$ and trended towards a steady stress state at depths greater than $0.060 \mathrm{~mm}$ [13]. Therefore, to assess the NSRS just below the surface and around this inflection point it is useful to remove material in very fine depth increments. Based on prior work [13, 16], it was decided that the depth profiles would graduate from fine increments up to the expected inflection point and then larger increments at greater depths. In this work depth is defined as the distance from the machined surface. However, since the machined surface is textured and the roughness varies among machining parameters it is useful to perform a depth correction. This is accomplished by measuring depth from the surface to a precision of $0.005 \mathrm{~mm}$ using a needlestyle depth gage (Mitutoyo model 7222) and making adjustments to account for the measured depths.
Table 1 Summary of parameters used to machine 206x101x28mm 7050-T7451 aluminum samples including cutting speed $\left(\mathrm{v}_{\mathrm{c}}\right)$, feed per tooth $\left(\mathrm{f}_{\mathrm{z}}\right)$, material removal rate $(\mathrm{Q})$, and average chip thickness $\left(\mathrm{h}_{\mathrm{m}}\right)$

\begin{tabular}{lllll}
\hline Mode & $\begin{array}{l}\text { Cutting speed, } \mathrm{v}_{\mathrm{c}} \\
(\mathrm{m} / \mathrm{min})\end{array}$ & $\begin{array}{l}\text { Feed per tooth, } \mathrm{f}_{\mathrm{z}} \\
(\mathrm{mm})\end{array}$ & $\begin{array}{l}\text { Material Removal Rate, } \\
\mathrm{Q}_{\mathrm{w}}\left(\mathrm{cm}^{3} / \mathrm{min}\right)\end{array}$ & $\begin{array}{l}\text { Average Chip } \\
\text { Thickness, } \mathrm{h}_{\mathrm{m}} \\
(\mathrm{mm})\end{array}$ \\
\hline Mode 1 & 200 & 0.04 & 7.6 & 0.023 \\
Mode 2 & 200 & 0.10 & 19.1 & 0.058 \\
Mode 3 & 200 & 0.20 & 38.2 & 0.115 \\
Mode 4 & 450 & 0.04 & 17.2 & 0.023 \\
\hline
\end{tabular}


Table 2 shows a summary of the depth profile increments and depths used for each of the measurement techniques. The depths used for both hole-drilling and slotting have increments of $0.0127 \mathrm{~mm}$ for 10 depths, increments of $0.0254 \mathrm{~mm}$ for six depths, and increments of $0.0508 \mathrm{~mm}$ for the final six depths, and a total depth of $0.584 \mathrm{~mm}$. The depths used for the $\cos (\alpha)$ XRD has one surface measurement followed by depth increments of $0.010 \mathrm{~mm}$ to a final depth of $0.120 \mathrm{~mm}$. The $\sin ^{2}(\psi)$ XRD measurements include one surface measurement followed by four increments of $0.020 \mathrm{~mm}$ and three increments of $0.040 \mathrm{~mm}$ to a final depth of $0.200 \mathrm{~mm}$.

\section{Measurement Layout}

The $206 \mathrm{~mm}$ by $102 \mathrm{~mm}$ machined face was subdivided into a grid consisting of $34 \mathrm{~mm}$ by $25.4 \mathrm{~mm}$ areas, as shown in Fig. 1. Surface residual stress measurements were made near the center of the grids (not shown) and the labels X\#Y\# are used to denote measurement locations.

Table 2 Summary of the depth schedule used for (left) slotting and hole-drilling techniques and (right) $\cos (\alpha)$ XRD and $\sin ^{2}(\psi)$ XRD techniques

\begin{tabular}{|c|c|c|c|c|}
\hline & $\begin{array}{l}\text { Hole- } \\
\text { drilling and } \\
\text { Slotting }\end{array}$ & & $\mathrm{XRD} \cos (\alpha)$ & XRD $\sin ^{2} \psi$ \\
\hline $\begin{array}{l}\text { Increment } \\
\mathrm{mm}\end{array}$ & Depth mm & $\begin{array}{c}\text { Increment } \\
\mathrm{mm}\end{array}$ & Depth mm & Depth mm \\
\hline 0 & - & 0 & 0 & 0 \\
\hline 0.0127 & 0.0127 & 0.010 & 0.010 & - \\
\hline 0.0127 & 0.0254 & 0.010 & 0.020 & 0.020 \\
\hline 0.0127 & 0.0381 & 0.010 & 0.030 & - \\
\hline 0.0127 & 0.0508 & 0.010 & 0.040 & 0.040 \\
\hline 0.0127 & 0.0635 & 0.010 & 0.050 & - \\
\hline 0.0127 & 0.0762 & 0.010 & 0.060 & 0.060 \\
\hline 0.0127 & 0.0889 & 0.010 & 0.070 & - \\
\hline 0.0127 & 0.1016 & 0.010 & 0.080 & 0.080 \\
\hline 0.0127 & 0.1143 & 0.010 & 0.090 & - \\
\hline 0.0127 & 0.127 & 0.010 & 0.100 & - \\
\hline 0.0254 & 0.1524 & 0.010 & 0.110 & - \\
\hline 0.0254 & 0.1778 & 0.010 & 0.120 & 0.120 \\
\hline 0.0254 & 0.2032 & 0.010 & 0.130 & - \\
\hline 0.0254 & 0.2286 & 0.010 & 0.140 & - \\
\hline 0.0254 & 0.254 & 0.010 & - & - \\
\hline 0.0254 & 0.2794 & 0.010 & - & 0.160 \\
\hline 0.0508 & 0.3302 & 0.010 & - & - \\
\hline 0.0508 & 0.381 & 0.010 & - & - \\
\hline 0.0508 & 0.4318 & 0.010 & - & - \\
\hline 0.0508 & 0.4826 & 0.010 & - & 0.200 \\
\hline 0.0508 & 0.5334 & & & \\
\hline 0.0508 & 0.5842 & & & \\
\hline
\end{tabular}

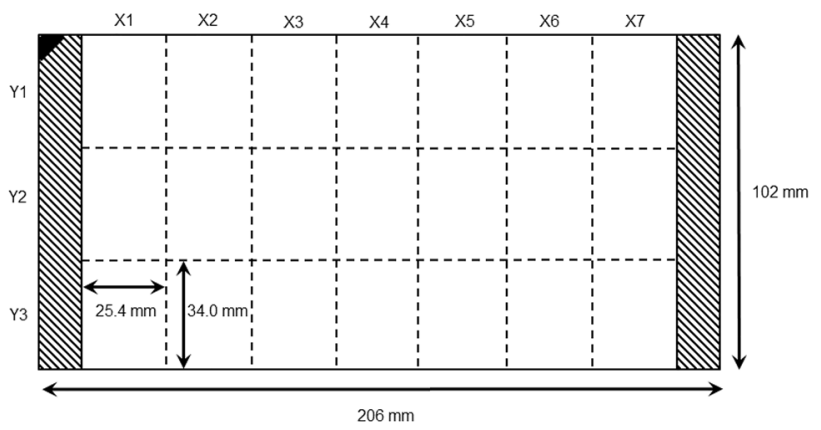

Fig. 1 Sample measurement grid layout where X\#Y\# indicates a grid location and the measurement is performed near the center of each subdivision; hatched areas are avoided, each $14.1 \mathrm{~mm}$ wide

All measurements are in areas of steady-state milling and away from edges and areas of lead-in (hatched areas shown in Fig. 1).

\section{Hole-drilling Technique}

The hole-drilling measurements follow ASTM E83713a [17], implementing specific suggestions from [16] to account for the small increments of hole depth given in Table 2. A strain gage rosette is used to measure three components $\left(\sigma_{\mathrm{xx}}, \sigma_{\mathrm{yy}}, \tau_{\mathrm{xy}}\right)$ of residual stress as functions of depth in a flat sample [17]. The strain gage used is an ASTM E837 type A rosette having three grids and a gage circle diameter of $5.13 \mathrm{~mm}$ bonded directly over the measurement location. Following the standard, a hole with an approximate diameter of $2 \mathrm{~mm}$ is cut in an orbital path with a $1.59 \mathrm{~mm}$ diameter end mill on an electric spindle attached to a bespoke, numerically controlled, precision mill. Hole-drilling uses high-speed cutting, as suggested in prior publications $[16,17]$, and a low material removal rate.

Each hole depth increment results in deformation at the boundary of the hole due to removal of stressed material [18]. Deformations are detected at the three strain gage grids. Recorded strain versus depth data are used to compute residual stress as a function of depth using established procedures $[17,18]$. Figure 2 a shows a location following a hole-drilling measurement.

Operator experience is important in executing key hole-drilling procedures. These include the alignment and bonding of the strain gage and soldering of lead wires to a strain indicator. Consistent cut increments and precise material removal are also important operator tasks that affect the resulting stress profile. This work uses a purpose-built, computer-controlled mill to accomplish the incremental depth removal with precision of $0.002 \mathrm{~mm}$. 


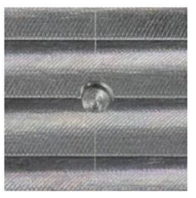

a
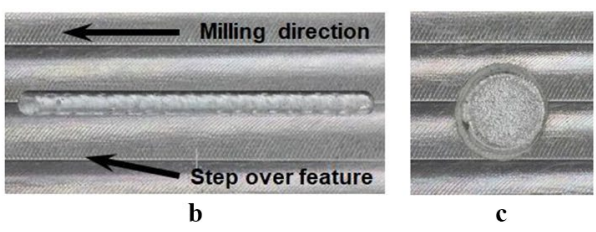

Fig. 2 Images of material removal associated with a hole-drilling measurement, $\mathbf{b}$ slotting measurement, and $\mathbf{c}$ XRD etch pit on sample B4. The distance between step over features is $4 \mathrm{~mm}$. The diameter of the a hole is approximately $2 \mathrm{~mm}$, the length of the b slot is $24 \mathrm{~mm}$ and its width is $1.8 \mathrm{~mm}$, and the diameter of the $\mathbf{c}$ etch pit is approximately $5 \mathrm{~mm}$

\section{Slotting Technique}

The slotting technique is essentially one-dimensional holedrilling. A single component of residual stress is measured by cutting a slot perpendicular to the desired stress direction. Similar to hole-drilling, incremental cuts are made into the depth and strain perpendicular to the slot is measured as a function of cut depth. The slotting technique uses a uniaxial strain gage. Figure $2 b$ shows a location following slotting measurement. As with hole-drilling, operator experience is required to limit the influence of methodological issues on the consistency and precision of the measurement. The slot is cut using the same purpose-built mill used for hole-drilling.

\section{Depth Correction}

For both hole-drilling and slotting, the final depth of the feature (hole or slot) is used to compute an offset between the intended depth schedule (Table 2 ) and the actual depths of measurement (offset $=$ measured final depth - intended final depth). This offset is then added to all depths and the resulting offset-corrected depths used with observed strain data to compute residual stress; the offset-corrected depths are also used to report residual stress versus depth profiles. The depth offset reflects a difference between the true surface height and the depth readout of the precision mill which can be controlled during set-up but not to better than about $0.025 \mathrm{~mm}$; the value of the depth corrections (for holedrilling) is described later, under Discussion. Precise final feature depth measurements require the removal of the strain gage and associated adhesive using an appropriate solvent.

\section{X-ray Diffraction $(\cos (\mathbf{a}))$ Technique}

The first application of XRD in this study was facilitated by a Pulstec $\mu$-X360s x-ray residual stress measurement system which uses the $\cos (\alpha)$ procedure as outlined by Tanaka [19]. The $\cos (\alpha)$ technique utilizes a $2 \mathrm{D}$ detector to obtain
Table 3 Summary of radiographic and reference values used in $\sin ^{2}(\psi)$ XRD analysis

\begin{tabular}{ll}
\hline Parameter & Value \\
\hline $\mathrm{s}_{1}$ & $-5.11 \cdot 10^{-6}\left(\mathrm{MPa}^{-1}\right)$ \\
$\frac{1}{2} \mathrm{~s}_{2}$ & $19.54 \cdot 10^{-6}\left(\mathrm{MPa}^{-1}\right)$ \\
$\mathrm{E}$ & $69 \cdot 10^{3}(\mathrm{MPa})$ \\
$\mathrm{v}$ & 0.35 \\
$\mathrm{~d}_{311}$ & $1.221059(\dot{\mathrm{A}})$ \\
$2 \theta_{\mathrm{Cr}}$ & $139.07^{\circ}$ \\
\hline
\end{tabular}

the full Debye-Scherrer ring which is then fitted to estimate the strain as a function of the azimuthal angle $\alpha$. The inplane normal component of stress is then calculated as being linearly proportional to the strain gradients with respect to $\cos (\alpha)$ and $\sin (\alpha)$.

The experimental setup uses a chromium tube to produce $\mathrm{x}$-rays at a wavelength of $2.29093 \AA$. The source output is $30 \mathrm{kV}$ with a current of $1 \mathrm{~mA}$ and an exposure time between 15 and $30 \mathrm{~s}$. The x-rays are projected through a $1 \mathrm{~mm}$ diameter collimator at an incident angle of $25^{\circ} \pm 1^{\circ}$ relative to the surface. This produces a scan area of approximately $2 \mathrm{~mm}$ diameter at the sample surface.

To measure NSRS as a function of depth an emersion electrolytic polishing technique was used to incrementally remove layers of material. A current of 4 amps with an active time of $15 \mathrm{~s}$ was used to achieve material layer removal of $0.01 \pm 0.0025 \mathrm{~mm}$ to $0.02 \pm 0.0025 \mathrm{~mm}$ and provided an approximately flat measurement pit. Since the $\mu$-X360s measures one component of stress per exposure, the sample was rotated 90 degrees at each depth increment to measure $\sigma_{\mathrm{xx}}$ and $\sigma_{\mathrm{yy}}$. Figure 2c shows a location following a $\cos (\alpha)$ measurement. The Mitutoyo 7222 needle-style depth gage was used to measure etch-pit depth at each increment and the observed depth used to report stress versus depth profiles.

\section{X-ray Diffraction $\left(\sin ^{2}(\psi)\right)$ Technique}

A dual-circuit X-ray diffractometer of the type Seifert XRD 3003TT, equipped with a chromium tube and a spatially resolved detector, is used to record the NSRS as a function of depth using the $\sin ^{2}(\psi)$ method [20-22]. The measuring spot is limited by a $2 \mathrm{~mm}$ point collimator. For measurement on the aluminum plates, the tilting range, $\psi$, varies from $-45.0^{\circ}$ to $+45.0^{\circ}$ with a total of 9 tilting positions. For the determination of the net plane distances, $\mathrm{d}_{311}$, the intensity over a $2 \theta$ range between $134.0^{\circ}$ and $143.95^{\circ}$ at a step width of $0.05^{\circ}$ is recorded. The exposure time per measurement was $84 \mathrm{~s}$. The maximum $\mathrm{x}$-ray penetration is $0.011 \mathrm{~mm}$.

The $\mathrm{x}$-ray elastic constants $\mathrm{s}_{1}, 1 / 2 \mathrm{~s}_{2}$, and the reference values for the unstressed material are assumed to be the values 
of pure aluminum powder [21]. These values (empirically derived for aluminum outside this study) are shown in Table 3. The determined strain from the lattice plane spacings, $d$, from several scans are plotted over $\sin ^{2}(\psi)$ from the individual scans. A regression line is plotted through these points. The residual stress is calculated directly from the slope of the regression line multiplied by the elastic constant $1 / 2 \mathrm{~s}_{2}$ of the lattice plane.

The evaluation of the residual stress measurements was done with the software RayfleX developed by General Electric. The position of the diffraction peaks were determined using:

- Smoothing according to the Savitzky \& Golay algorithm over the full width half maximum.

- Linear background correction.

- Intensity Corrections: Lorentz, Polarization, Absorption (LPA).

- Parabolic fitting with a threshold of $70 \%$ of maximum intensity.

The measuring accuracy of the $\mathrm{x}$-ray diffractometer is determined by the manufacturer for plane specimen geometries with $\sigma= \pm 10 \mathrm{MPa}$. Measurements of stress versus depth were achieved by electrochemical etching. At each depth stress was measured at three rotations, $0^{\circ}, 45^{\circ}$, and $90^{\circ}$ relative to the $\mathrm{x}$-axis of the sample to determine $\sigma_{\mathrm{xx}}, \sigma_{\mathrm{yy}}$, and $\sigma_{\mathrm{xy}}$. Actual etch pit depths were measured at each increment and used to report stress versus depth profiles.

\section{Summary of Measurements}

NSRS was measured at multiple locations on sample B4 using all four techniques to establish their repeatability. This included six hole-drilling, five slotting, three $\cos (\alpha)$ XRD, and three $\sin ^{2}(\psi)$ XRD measurements at various locations. This data was used to calculate the repeated average and standard deviation of stress versus depth across the four measurement techniques. To investigate the effect of different feed per tooth and cutting speeds, single measurements were made on samples A12, B15, B5, and A22 with each technique (hole-drilling, slotting, $\cos (\alpha) \mathrm{XRD}$, and $\sin ^{2}(\psi)$ XRD). The data from these measurements are then assessed for consistency with trends found in prior publications. These measurements, and the locations where they were made, are summarized in Table 4. Only $\sigma_{y y}$ is reported when investigating the effect of different feeds and speeds since some of the measurement techniques used in this work were not used to assess $\sigma_{\mathrm{xx}}$ or $\sigma_{\mathrm{xy}}$.

\section{Validation of NSRS Data Using Wafer Distortion Experiments}

Validation of the measured NSRS is accomplished through comparison of a simple distortion experiment and a simple model. The distortion experiment starts with the removal of a $25 \mathrm{~mm}$ wide by $25 \mathrm{~mm}$ long by $25 \mathrm{~mm}$ thick cube from the larger machined samples by wire electric discharge machining (EDM). The cube is then rotated $90^{\circ}$ about the $y$-axis and a $1 \mathrm{~mm}$ thick wafer, including the machined surface, is cut from the cube by wire EDM. Figure 3 shows both stages of this setup. The wire EDM surface of the wafer is then scanned using a laser profilometer at points with a $0.2 \mathrm{~mm}$ spacing across both the width and length of the wafer. This provides a map of the out-of-plane distortion of the wafer, which is assumed to result from the milling NSRS.
Table 4 Summary of samples and measurements showing milling mode, measurement type and measurement location (location codes such as $\mathrm{X} 4 \mathrm{Y} 1 \mathrm{p} 5$ indicate measurements performed between sites like $\mathrm{X} 4 \mathrm{Y} 1$ and $\mathrm{X} 4 \mathrm{Y} 2)$

\begin{tabular}{lllll}
\hline Sample & Mode & Measurement Types & Locations & $\begin{array}{l}\text { Numbers of } \\
\text { Measure- } \\
\text { ments }\end{array}$ \\
\hline A12 & Mode 1 & Hole-drilling & X4Y2 & 1 \\
& & Slotting & X5Y2 & 1 \\
& & $\cos (\alpha)$ XRD & X3Y2 & 1 \\
& & $\sin ^{2}(\psi)$ XRD & X2Y2 & 1 \\
B15 & Mode 2 & Hole-drilling & X4Y2 & 1 \\
& & Slotting & X5Y2 & 1 \\
& & $\cos (\alpha)$ XRD & X3Y2 & 1 \\
B4 & Mode 3 & Hole-drilling & X2Y1, X4Y1, X4Y2, X6Y1, X6Y2, X6Y3 & 6 \\
& & Slotting & X3Y1, X3Y3, X4p5Y1p5, X4p5Y2p5, X5Y2 & 5 \\
& & $\cos (\alpha)$ XRD & X3p5Y1p5, X5Y1p5, X6Y1p5 & 3 \\
& & $\sin { }^{2}(\psi)$ XRD & X2Y2, X2Y3, X4Y3 & 3 \\
B5 & Mode 4 & Hole-drilling & X5Y2 & 1 \\
& & Slotting & X4Y2 & 1 \\
& & $\cos (\alpha)$ XRD & X3Y2 & 1 \\
A22 & Mode 4 & $\sin ^{2}(\psi)$ XRD & X2Y2 & 1 \\
\hline
\end{tabular}



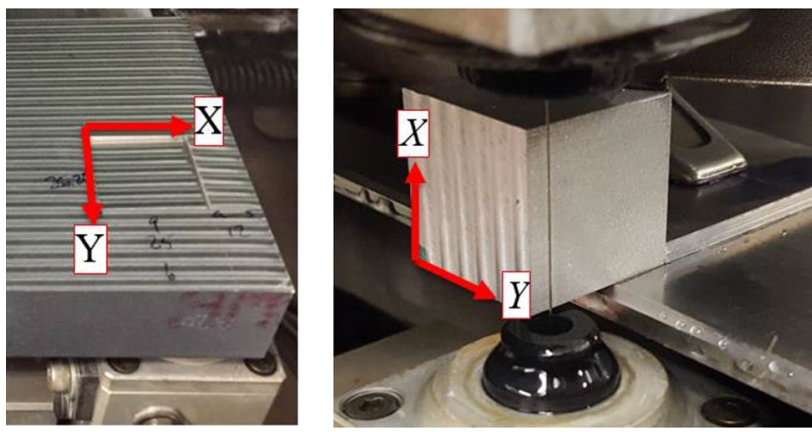

Fig. 3 Wire EDM experiment setup used in the wafer distortion experiments including a removal of $25 \mathrm{~mm}$ cube from the larger sample, and $\mathbf{b}$ cutting of the wafer $1 \mathrm{~mm}$ below the machined surface

A finite element model is used to determine the out-ofplane deformation of the wafer that would be caused by measured NSRS. The finite element mesh has a uniform $0.508 \mathrm{~mm}$ element size in the $25 \times 25 \mathrm{~mm}$ plane of the wafer. Element out-of-plane thickness is small $(0.01 \mathrm{~mm})$ at the machined surface and increases with depth to $0.14 \mathrm{~mm}$ at the EDM surface over twenty elements. The elements used are 8-noded linear brick elements and the mesh is shown in Fig. 4. The material is assumed linearly elastic with $\mathrm{E}=71,000 \mathrm{MPa}$ and $\nu=0.33$. Boundary conditions necessary to suppress rigid body motion are applied. Measured NSRS versus depth data are linearly interpolated at the element centroids and imposed as an initial condition. Equilibrium is then determined which provides a distorted shape. The displacements in the $\mathrm{z}$-direction, $\mathrm{u}_{3}$, are collected and used in comparison with the results from the distortion experiments. Similarity between distortion observed in the experiment and computed by the companion finite element model would indicate consistency between the residual stress and distortion data.

\section{Results}

\section{Surface Topography}

Figure 5 shows 3D surface scans of the samples machined with four different parameter sets. The measurement field size is $8.1 \mathrm{~mm}$ long and $2.65 \mathrm{~mm}$ wide. The short direction

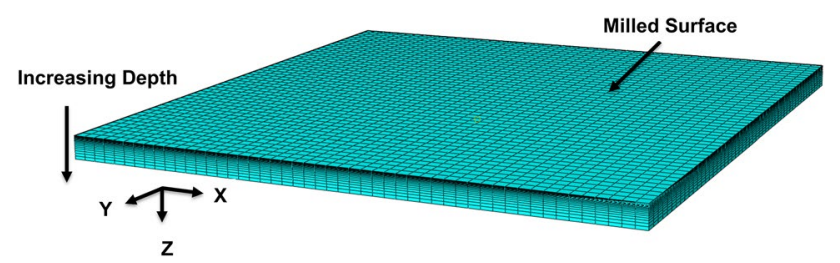

Fig. 4 Image of finite element mesh used in the wafer distortion model
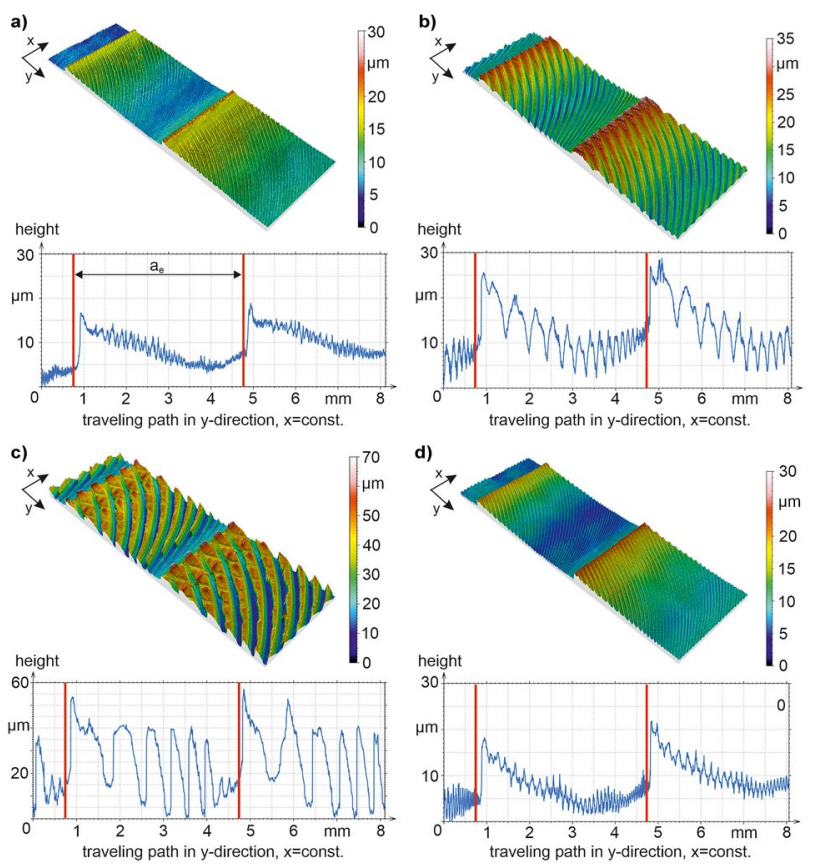

Fig. 5 Surface roughness profiles along y direction and 3D optical surface scans for a mode $1, \mathbf{b}$ mode $2, \mathbf{c}$ mode 3 , and $\mathbf{d}$ mode 4

(x) represents the feed direction. The travelling path of each cutter is clearly visible in the form of grooves. The scans as well as the surface roughness values (see Table 5) show that the roughness increases with an increased feed per tooth. A maximum surface roughness of $\mathrm{Sz}=0.071 \mathrm{~mm}$ is reached for machining with the highest feed per tooth, $\mathrm{f}_{\mathrm{z}}=0.2 \mathrm{~mm}$ (Fig. 5c, mode 3). Increased cutting speed has no major impact on the surface roughness (similarity of mode 1 (Fig. 5a) and mode 4 (Fig. 5d)). Furthermore, the pass width $\left(\mathrm{a}_{\mathrm{e}}=4 \mathrm{~mm}\right)$ is visible in the scans and the $2 \mathrm{D}$ roughness profiles (marked by red lines).

\section{Residual Stress Measurement Repeatability}

Figure 6 shows repeated measurements of the transverse NSRS (orthogonal to the machining path) using each NSRS

Table 5 Surface Roughness values according to ISO 25,178 (Sa arithmetical mean height, $\mathrm{Sz}$ maximum height, $\mathrm{Sq}$ root mean square height)

\begin{tabular}{lllccc}
\hline & $\begin{array}{l}\text { Cutting } \\
\text { speed, } \mathrm{v}_{\mathrm{c}}(\mathrm{m} / \\
\text { min })\end{array}$ & $\begin{array}{l}\text { Feed per } \\
\text { tooth, } \mathrm{f}_{\mathrm{z}} \\
(\mathrm{mm})\end{array}$ & $\mathrm{Sa}(\mu \mathrm{m})$ & $\mathrm{Sz}(\mu \mathrm{m})$ & $\mathrm{Sq}(\mu \mathrm{m})$ \\
\hline Mode 1 & 200 & 0.04 & 3.09 & 24.0 & 3.69 \\
Mode 2 & 200 & 0.10 & 4.73 & 36.7 & 5.85 \\
Mode 3 & 200 & 0.20 & 11.6 & 71.2 & 13.1 \\
Mode 4 & 450 & 0.04 & 3.41 & 27.8 & 4.25 \\
\hline
\end{tabular}



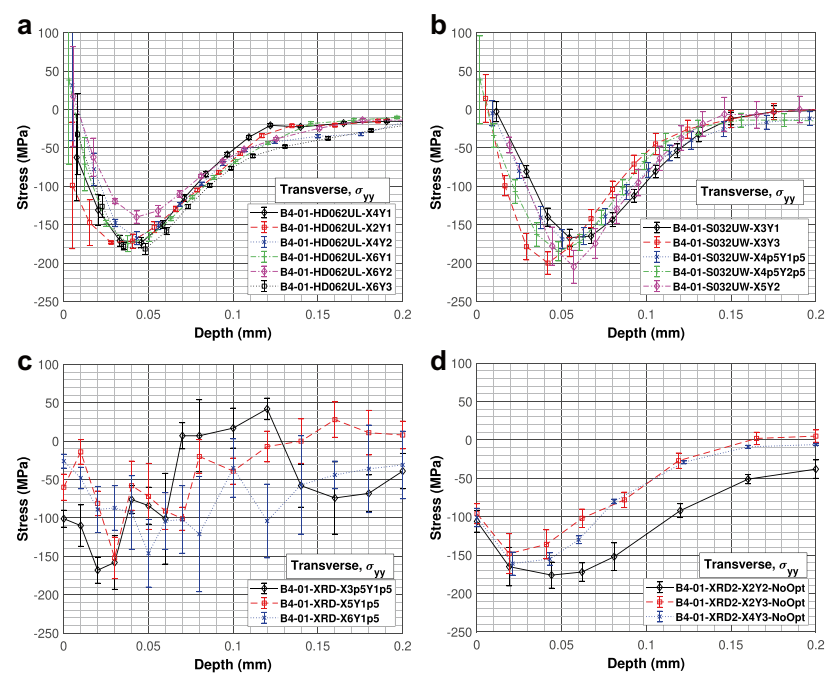

Fig. 6 Repeat measurements of transverse residual stress $\left(\sigma_{\mathrm{yy}}\right)$ on sample B4 with a cutting speed of $200 \mathrm{~m} / \mathrm{min}$ and a feed per tooth length of $0.2 \mathrm{~mm}$ for a hole-drilling, b slotting, $\mathbf{c} \cos (\alpha) \mathrm{XRD}, \mathbf{d}$ $\sin ^{2}(\psi)$ XRD

measurement technique on sample B4 at various locations over the milled surface (location code defined in Fig. 1). A $\sqrt{ }$-shaped stress distribution is evident in results for hole-drilling, slotting, and $\sin ^{2}(\psi)$ XRD. For each method, except $\cos (\alpha)$ XRD, there is consistency in the depth and magnitude of NSRS, and the return to $0 \mathrm{MPa}$ at depth of $0.2 \mathrm{~mm}$. The range of NSRS at specific depths varies by technique with $\sin ^{2}(\psi)$ XRD being more repeatable at shallow depths $(\leq 0.02 \mathrm{~mm})$ than hole-drilling or slotting and the converse being true at deeper depths $(\geq 0.05 \mathrm{~mm})$.

Figure 7 shows averaged stress and standard deviation versus depth of the transverse NSRS for all measurement techniques. This is done by interpolating independent measurements to the respective depth schedules in Table 2 and calculating the average and standard deviation at each depth. From Fig. 7a the trend in averaged NSRS data is consistent for each method except $\cos (\alpha)$ XRD. The data

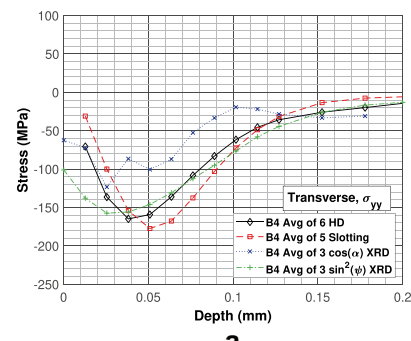

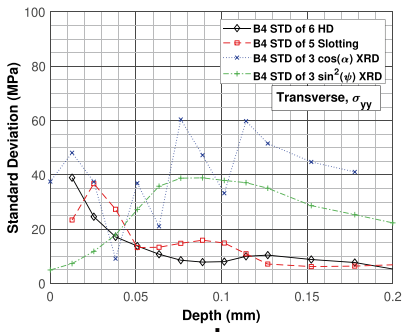

b
Fig. 7 Comparison of transverse residual stress $\left(\sigma_{y y}\right)$ for hole-drilling, slotting, $\cos (\alpha)$ XRD, and $\sin ^{2}(\psi)$ XRD: a the average of repeated measurements versus depth and $\mathbf{b}$ the standard deviation versus depth from hole-drilling, slotting, and $\sin ^{2}(\psi)$ XRD show maximum compressive stress of $-170 \pm 15 \mathrm{MPa}$ and a depth of maximum compressive NSRS of $0.04 \pm 0.01 \mathrm{~mm}$. In Fig. $7 \mathrm{~b}$ the precision varies by technique and depth of NSRS. Data from hole-drilling and slotting techniques show increasing improvement in standard deviation from 25 and $40 \mathrm{MPa}$, respectively, at $0.015 \mathrm{~mm}$ to approximately $10 \mathrm{MPa}$ at depths greater than $0.120 \mathrm{~mm}$. Conversely data from $\sin ^{2}(\psi)$ XRD show increasing standard deviation with increasing depth from $5 \mathrm{MPa}$ at the surface to a maximum standard deviation of $40 \mathrm{MPa}$ at $0.085 \mathrm{~mm}$. The $\cos (\alpha)$ XRD precision fluctuates with depth and has the highest standard deviation.

Figure 8 shows averaged repeatability and standard deviation versus depth for the longitudinal NSRS component (which was not measured by slotting). Figure 8a shows that data from hole-drilling and $\sin ^{2}(\psi)$ XRD agree well. Unlike results for transverse NSRS, $\cos (\alpha)$ XRD data for longitudinal NSRS agree fairly well with the data from hole-drilling and $\sin ^{2}(\psi)$ XRD. Hole-drilling and $\sin ^{2}(\psi)$ XRD data have maximum compressive NSRS of $-150 \pm 20 \mathrm{MPa}$ while $\cos (\alpha)$ XRD data have maximum compressive NSRS of $-200 \pm 25 \mathrm{MPa}$. Hole-drilling and $\sin ^{2}(\psi)$ XRD data show the depth of maximum compressive NSRS is $0.050 \mathrm{~mm}$ while $\cos (\alpha)$ XRD data show $0.040 \mathrm{~mm}$. In Fig. 8b the XRD data exhibit increasing standard deviation with increasing depth while hole-drilling data show the opposite, which is a trend also observed for repeatability of the transverse NSRS component.

Figure 9 shows averaged stress and standard deviation versus depth for the shear component of NSRS (which was available only for hole-drilling and $\sin ^{2}(\psi)$ XRD techniques). The data exhibit low levels of stress with moderate differences with maximum shear NSRS of $-55 \pm 12 \mathrm{MPa}$ for hole-drilling and $-30 \pm 7 \mathrm{MPa}$ for $\sin ^{2}(\psi)$ XRD. The depth of maximum shear NSRS is the same for both techniques, $0.025 \mathrm{~mm}$. In Fig. $9 \mathrm{~b}$ the XRD data exhibit increasing standard deviation with depth being $10 \mathrm{MPa}$ at the surface to around $35 \mathrm{MPa}$ at

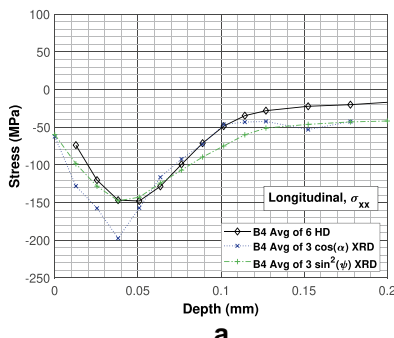

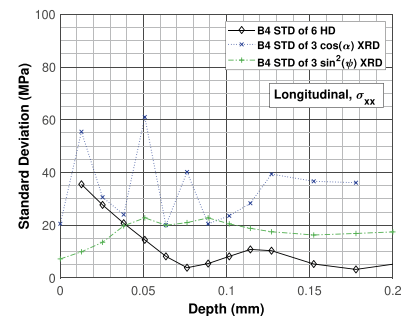

b
Fig. 8 Comparison of longitudinal residual stress $\left(\sigma_{\mathrm{xx}}\right)$ for holedrilling, slotting, $\cos (\alpha)$ XRD, and $\sin ^{2}(\psi)$ XRD: a the average of repeated measurements versus depth and $\mathbf{b}$ the standard deviation versus depth 

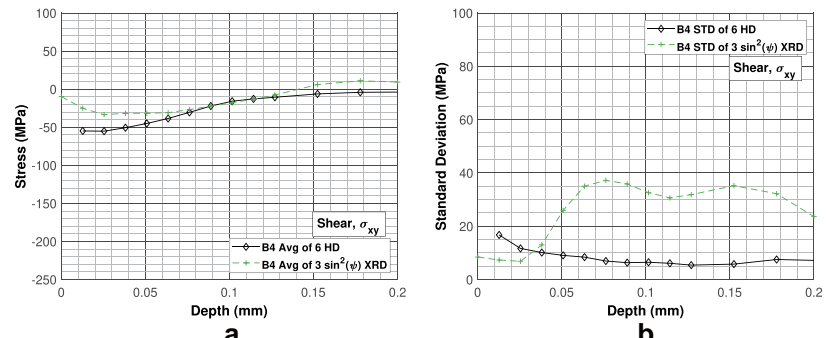

Fig. 9 Comparison of shear residual stress $\left(\sigma_{\mathrm{xy}}\right)$ for hole-drilling, and $\sin ^{2}(\psi)$ XRD (shear stress was not measured using slotting or $\cos (\alpha)$ $\mathrm{XRD}$ ): $\mathbf{a}$ the average of repeated measurements versus depth and $\mathbf{b}$ the standard deviation versus depth

depth $>0.06 \mathrm{~mm}$. The hole-drilling data show decreasing standard deviation with depth, being $15 \mathrm{MPa}$ at $0.01 \mathrm{~mm}$ and around $5 \mathrm{MPa}$ at depth $>0.08 \mathrm{~mm}$.

\section{Variations in Feed Per Tooth}

Figure 10 shows the transverse NSRS in samples cut with the same cutting speed but with different feed per tooth, $\mathrm{f}_{\mathrm{z}}=0.04 \mathrm{~mm}$ (shown in black), $\mathrm{f}_{\mathrm{z}}=0.1 \mathrm{~mm}$ (red), and $\mathrm{f}_{\mathrm{z}}=0.2 \mathrm{~mm}$ (blue). The overall trend for all conditions and all measurement techniques is a layer of compressive NSRS. For most techniques the stress data trend toward $0 \mathrm{MPa}$ for depth greater than $0.15 \mathrm{~mm}$ but $\sin ^{2}(\psi)$ XRD data remain compressive for all depths (-50 to $-15 \mathrm{MPa})$. Data from hole-drilling, slotting, and $\sin ^{2}(\psi)$ XRD show monotonically increasing depth of stress with increasing feed per tooth (no data are available from $\sin ^{2}(\psi)$ XRD for
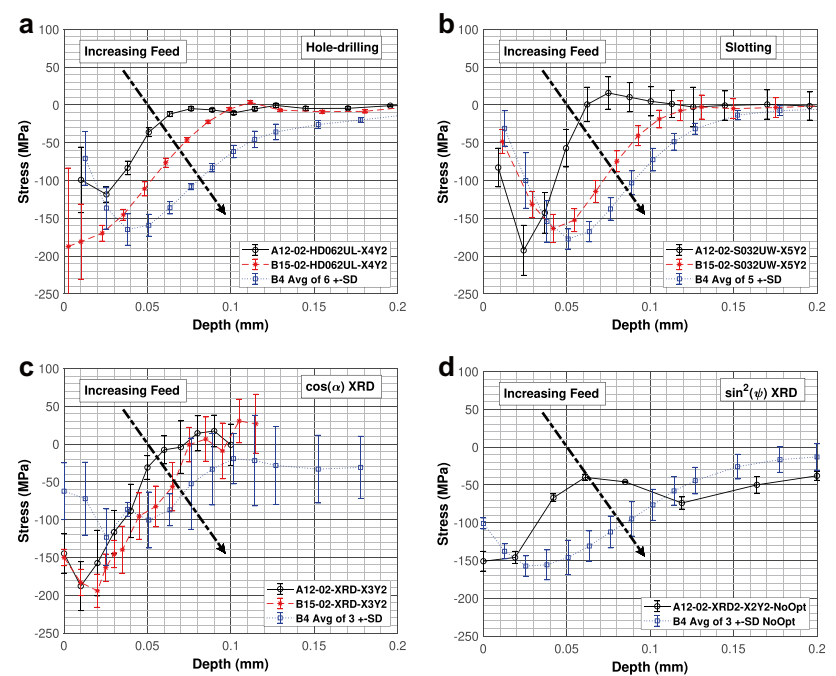

Fig. 10 Comparison of transverse residual stress $\left(\sigma_{\mathrm{yy}}\right)$ in samples machined at a fixed cutting speed of $200 \mathrm{~m} / \mathrm{min}$ and variable feed per tooth for a hole-drilling, b slotting, $\mathbf{c} \cos (\alpha) \mathrm{XRD}, \mathbf{d} \sin ^{2}(\psi) \mathrm{XRD}$ $\mathrm{f}_{\mathrm{z}}=0.1 \mathrm{~mm}$ ), a trend that agrees with prior work [10-13]. The $\cos (\alpha)$ XRD data show this trend weakly and they also exhibit considerable uncertainty. The maximum compressive NSRS from slotting and $\sin ^{2}(\psi)$ XRD techniques is largely invariant with $\mathrm{f}_{\mathrm{z}}$, being -150 to $-160 \mathrm{MPa}$ for $\sin ^{2}(\psi)$ XRD and -160 to -190 MPa for slotting. The maximum compressive NSRS from hole-drilling are similar to those from slotting for $\mathrm{f}_{\mathrm{z}}=0.1$ and $0.2 \mathrm{~mm}$, but is much less compressive for $\mathrm{f}_{\mathrm{z}}=0.04 \mathrm{~mm}$. The depth of maximum compressive NSRS from hole-drilling and slotting data are similar for $\mathrm{f}_{\mathrm{z}}=0.2$ and $0.04 \mathrm{~mm}$, being 0.04 and $0.025 \mathrm{~mm}$ for holedrilling and 0.05 and $0.025 \mathrm{~mm}$ for slotting. For $\mathrm{f}_{\mathrm{z}}=0.1 \mathrm{~mm}$ the data from hole-drilling shows the depth of maximum compressive NSRS at the surface while data from slotting show $0.04 \mathrm{~mm}$. The depth of maximum compressive NSRS from $\sin ^{2}(\psi)$ XRD data appear closer to the surface around $0.03 \mathrm{~mm}$ for $\mathrm{f}_{\mathrm{z}}=0.2 \mathrm{~mm}$ and at the surface for $\mathrm{f}_{\mathrm{z}}=0.04 \mathrm{~mm}$.

\section{Variations in Cutting Speed}

Figure 11 shows transverse NSRS in samples cut with the same feed per tooth but different cutting speeds, $200 \mathrm{~m} / \mathrm{min}$ (shown in black) and $450 \mathrm{~m} / \mathrm{min}$ (green). The data from hole-drilling, slotting, and $\cos (\alpha)$ XRD show that NSRS differs slightly for changes in cutting speed, a trend in agreement with one prior study [11] but in contrast to others [12, 13]. Data from the $\sin ^{2}(\psi)$ XRD show this trend sporadically (note that the $\mathrm{v}_{\mathrm{c}}=450 \mathrm{~m} / \mathrm{min}$ XRD data are from a different sample than used for hole-drilling, slotting, and $\cos (\alpha)$ XRD measurements). The hole-drilling, slotting, and $\cos (\alpha)$ data show NSRS trends to $0 \mathrm{MPa}$ after $0.08 \mathrm{~mm}$ while $\sin ^{2}(\psi)$
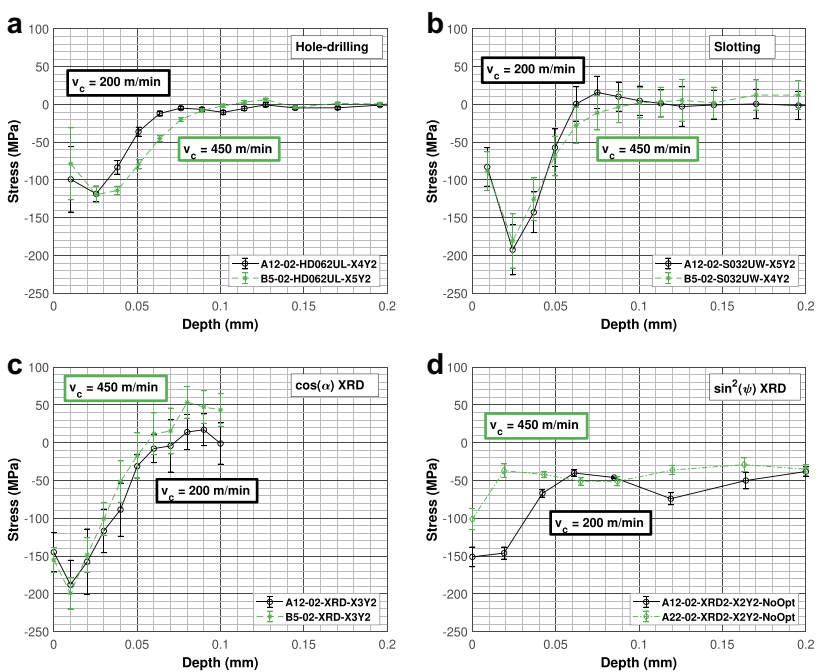

Fig. 11 Comparison of transverse residual stress $\left(\sigma_{\mathrm{yy}}\right)$ for machining at a fixed feed per tooth of $0.04 \mathrm{~mm}$ and variable cutting speed for a hole-drilling, b slotting, $\mathbf{c} \cos (\alpha)$ XRD, $\mathbf{d} \sin ^{2}(\psi)$ XRD (note that $\sin ^{2}(\psi)$ XRD data were gathered on a different sample) 
XRD data remain compressive (-30 to $-70 \mathrm{MPa})$. Data from slotting and $\cos (\alpha)$ XRD show maximum compressive NSRS of -190 MPa while hole-drilling data show -120 MPa. The depth of maximum compressive NSRS is similar for hole-drilling and slotting data at $0.025 \mathrm{~mm}$ while the $\cos (\alpha)$ XRD data show a maximum compressive depth of $0.01 \mathrm{~mm}$.

\section{Validation Using Thin Wafer Distortion}

Figure 12 shows averaged NSRS data from the hole-drilling and $\sin ^{2}(\psi)$ XRD measurements that are used as input to the wafer distortion model. For depths less than $0.12 \mathrm{~mm}$ the longitudinal and transverse NSRS data from hole-drilling and $\sin ^{2}(\psi)$ XRD are similar both in magnitude and depth of maximum compressive NSRS. For depths greater than $0.12 \mathrm{~mm}$ hole-drilling data trend back to $0 \mathrm{MPa}$ while data from $\sin ^{2}(\psi)$ XRD show compressive longitudinal and transverse NSRS and tensile shear NSRS. The longitudinal and transverse maximum compressive NSRS are similar for hole-drilling and $\sin ^{2}(\psi)$ XRD (-150 to $-160 \mathrm{MPa})$. The shear peak NSRS magnitude is $-55 \mathrm{MPa}$ for hole-drilling and $-35 \mathrm{MPa}$ for $\sin ^{2}(\psi)$ XRD. In the wafer model, NSRS was held constant beyond maximum measured depths, being $0.6 \mathrm{~mm}$ for hole-drilling and $0.2 \mathrm{~mm}$ for $\sin ^{2}(\psi)$ XRD up to the thickness of the wafer model $(1.0 \mathrm{~mm})$.

Figure 13 shows the color maps of measured and calculated wafer distortion. The color maps represent looking down at the milled surface with positive distortion in the z-direction (into the surface). The measured wafer (Fig. 13a) shows that the machined surface becomes convex when the wafer is cut free and the largest distortion occurs at the $(0,0)$ and $(25,25) \mathrm{mm}$ corners. The convexity is consistent with compressive NSRS from machining. The distortion color maps (Fig. 13b and Fig. 13c) show that model and measured distortions are comparable, with the model using hole-drilling data as input having a closer match to the measurement data than the model using $\sin ^{2}(\psi)$ XRD data.

Figure 14 shows corner to corner line plots of measured and calculated distortion. The general shape of the measured and calculated displacement curves agree well with little difference at the center $(\mathrm{x}=12.5 \mathrm{~mm})$ and larger differences occurring
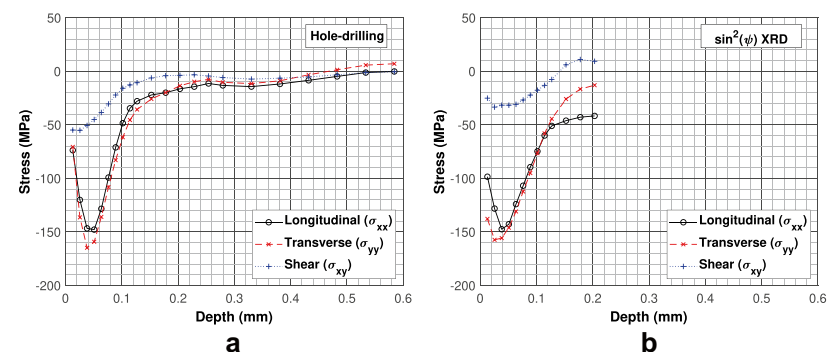

Fig. 12 Measured NSRS data on sample B4 used as inputs in the wafer distortion model $\mathbf{a}$ average of six hole-drilling and $\mathbf{b}$ average of three $\sin ^{2}(\psi)$ XRD measurements

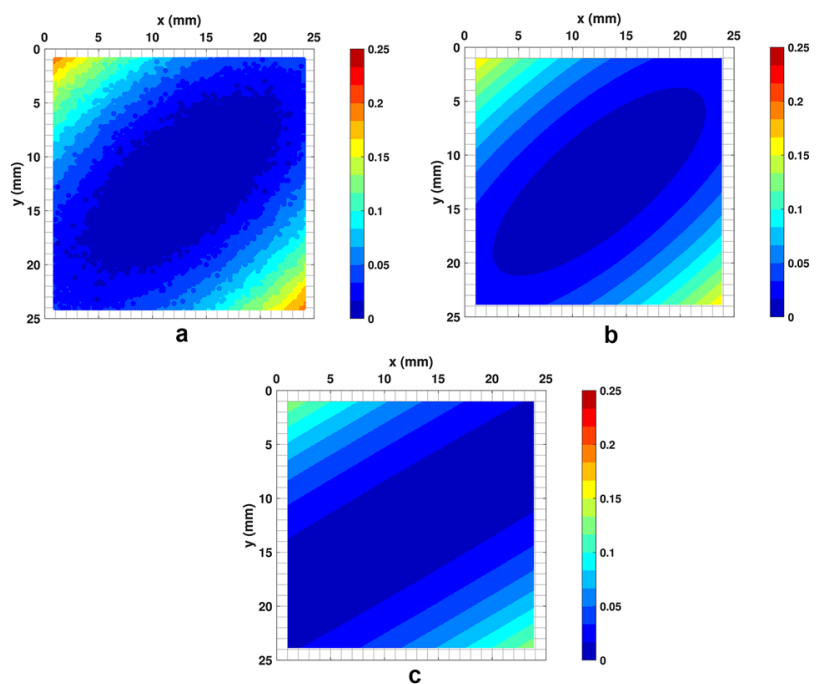

Fig. 13 Color maps of wafer topography for sample B4 a measured data, b calculated with hole-drilling stress input, and $\mathbf{c}$ calculated with $\sin ^{2}(\psi)$ XRD stress input (color scale in $\mathrm{mm}$ )

near the edges ( 1.5 and $23.5 \mathrm{~mm})$. Along the line from $(0,0)$ to $(25,25) \mathrm{mm}$ (Fig. 14a) the measured data have a peak to valley distortion of $0.190 \mathrm{~mm}$, while the hole-drilling and $\sin ^{2}(\psi)$ XRD models have peak to valley distortion of $0.165 \mathrm{~mm}$ and $0.135 \mathrm{~mm}$, respectively. Along the line from $(0,25) \mathrm{mm}$ to $(25,0) \mathrm{mm}$ (Fig. 14b), the measured data have a peak to valley distortion of $0.040 \mathrm{~mm}$, while the models using holedrilling and $\sin ^{2}(\psi)$ XRD data have peak to valley distortion of $0.020 \mathrm{~mm}$ and $0.005 \mathrm{~mm}$, respectively.

\section{Discussion}

\section{Methodological Issues}

The work reported here shows that four different measurement techniques provide generally comparable near-surface
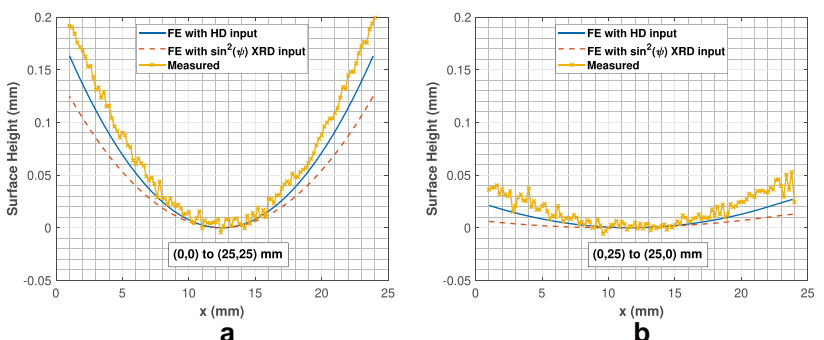

Fig. 14 Observed wafer topography data (lines with points) from sample B4 compared with output from FE models (lines) that use as input residual stress data from either hole-drilling (solid line) or $\sin ^{2}(\psi)$ XRD (dashed line); data plotted along paths from corner-tocorner: $\mathbf{a}(0,0)$ to $(25,25) \mathrm{mm}$, and $\mathbf{b}(0,25)$ to $(25,0) \mathrm{mm}$ 
residual stress versus depth profile data in milled aluminum workpieces, but with some differences in precision and bias. When multiple measured depth profiles are averaged, the four techniques provide similar depth profile shapes for all milling conditions, being a root shape $(\sqrt{ })$ that is consistent with prior published work (e.g., [9]). The maximum stress levels and the depths of the near-surface compressive layer are affected by the milling parameters. The maximum compressive stress magnitudes range from -100 to $-200 \mathrm{MPa}$ with the maximum occuring at depths between 0.030 and $0.050 \mathrm{~mm}$. The largest differences between techniques occur at shallow depths $(<0.03 \mathrm{~mm})$.

The differences in measured NSRS between techniques may arise from specific methodological issues. One issue is defining depth below the machined surface since the various machining conditions produce surfaces with topography that is significant relative to the initial depth increments in the stress profiles, which are $0.01 \mathrm{~mm}$ (Table 1). Figure 5 shows that mode 1 (Fig. 5a) has a maximum surface height $\mathrm{Sz}$ of $0.024 \mathrm{~mm}$ and mode 3 (Fig. 5c) a maximum surface height of $0.071 \mathrm{~mm}$ (Table 5). For depths within the surface height, the sampling of the mechanical and diffraction techniques differs and therefore affects reported data (especially for initial points within the profile height $\mathrm{Sz}$ ). For the mechanical techniques, material is removed in a thin area (e.g., a disk for hole-drilling) at fixed depth increments. Early in the measurement, surface texture makes the material removal incomplete relative to what would occur for an ideal flat surface (see Fig. 15a). The incomplete material removal influences the mechanics of stress release and strain occurring at the gage locations, which introduces a potential systematic error. For the diffraction techniques, material is removed over a finite area that is less well defined. The first measurement is made at the surface, with no material removal, and integrates signal from grains at different depth positions. For subsequent depths, the diffraction volume remains non-flat, but the etch pit bottom generally flattens in response to etching over the first few depths (see Fig. 15b). The surface topography is
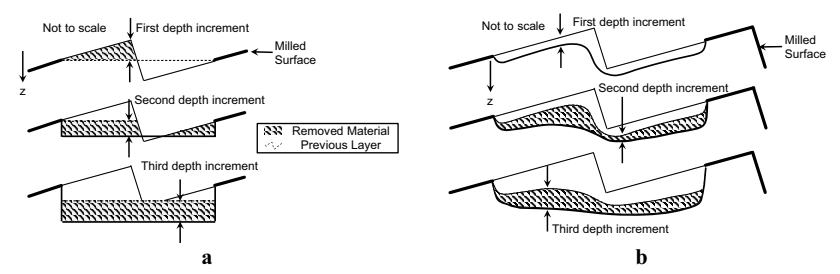

Fig. 15 Diagram depicting the incomplete material removal in a textured surface for three depth increments for a hole-drilling where the first depth increment removes a fraction of the intended material and subsequent increments remove larger segments of material and $\mathbf{b}$ XRD measurement where the first depth increment removes material while a majority of surface texture remains non-flat and subsequent increments begin to flatten the surface texture therefore likely to influence differently the mechanical and diffraction measurements at shallow depth, which may lead to differences between techniques. The data here (Fig. 7a and Fig. 8a) show the largest intermethod differences at shallow depths $(<0.05 \mathrm{~mm})$, where surface topography effects seem more important, and much smaller intermethod differences at moderate depths ( 0.05 to $0.10 \mathrm{~mm})$ where the effects seem less important.

For all techniques the measurement area (etch pit diameter, spot size, or hole diameter) is a few millimeters and bridges several of the topographic surface features (Fig. 5). This makes defining a zero-depth datum difficult but important, as the datum directly affects the resulting stress profiles. This work used procedures to control variation in the zerodepth datum. For the mechanical techniques this is accomplished by measuring the final cut depth and correcting all intended cut depths with an additive depth offset. The effect of the depth correction is significant, as shown for holedrilling in Fig. 16. Figure 16a shows repeated stress profile measurements determined using intended (uncorrected) depths of cut while Fig. 16b shows the same measurements after correcting each for the measured depth offset prior to computing stress. The depth correction improves precision (reduces scatter) even though the depth correction is rather small, ranging from a maximum of $0.025 \mathrm{~mm}$ (for B4-02HD062UL-X4Y1) to a minimum of $0.005 \mathrm{~mm}$ (for B4-02HD062UL-X6Y1), and with an average of $0.014 \mathrm{~mm}$. For $\mathrm{x}$-ray diffraction techniques, stress was reported at measured etch-pit depths, which may include a finite potential variation of the zero-depth datum in each measurement.

Additional methodological issues arose for the $\cos (\alpha)$ XRD technique. Examination of the Debye ring used in the $\cos (\alpha)$ analysis shows that most of the present measurements had low quality signal. Examples of two Debye rings are shown in Fig. 17, where the color and out-of-plane height represent intensity. The incompleteness of the rings in Fig. 17 is consistent with material texture and preferred grain orientation [23], which is typical of rolled aluminum
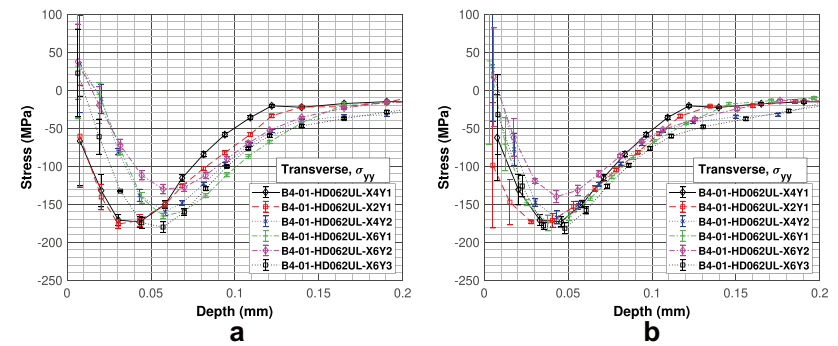

Fig. 16 Comparison of transverse residual stress $\left(\sigma_{\mathrm{yy}}\right)$ for 6 hole-drilling measurements on sample B4 where depth corrections a are not applied and $\mathbf{b}$ are applied 

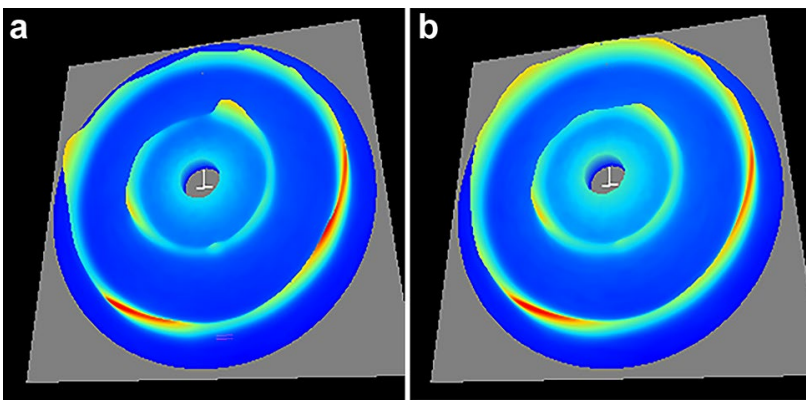

Fig. 17 Comparison of Debye rings for measurements of NSRS in mode 3 sample A20 at a depth of $0.02 \mathrm{~mm}$ along the a transverse direction $\left(\sigma_{\mathrm{yy}}\right)$, and $\mathbf{b}$ longitudinal direction $\left(\sigma_{\mathrm{xx}}\right)$

plate. The Debye rings were generally less uniform for $\sigma_{\mathrm{yy}}$ (Fig. 17a) and somewhat more uniform for $\sigma_{x x}$ (Fig. 17b). The difference in the Debye ring quality in each direction is consistent with the NSRS data in Fig. 7 and Fig. 8, where the $\cos (\alpha)$ XRD results are less consistent with data from other techniques for $\sigma_{\mathrm{yy}}$ (Fig. 7), which had a lower quality Debye ring, and more consistent for $\sigma_{\mathrm{xx}}$ (Fig. 8), which had a higher quality Debye ring.

\section{Value of Wafer Experiments}

The wafer distortion experiments and companion finite element model are complements to residual stress measurements as they allow a determination of the usefulness of the NSRS data by assessing consistency between distortion observed and distortion computed from measured residual stress depth profiles (see Fig. 13). While it is difficult to ascribe significance to differences between two sets of stress versus depth profiles (Fig. 12), the similarity of observed and computed distortion provides a practical comparative basis. The wafer experiment is fit to purpose here because the present interest motivating measurement of the depth profile is the connection between milling parameters and machining distortion. The high degree of consistency between the observed distortion of Fig. 13a and the computed distortion of Fig. 13b suggests the stress profiles from the hole-drilling technique are useful in understanding distortion; the same could be said for stress profiles from the $\sin ^{2}(\psi)$ XRD technique, but with a lower level of agreement. The line plots of Fig. 14 provide quantitative backing for visual observations from the color maps of Fig. 13. The wafer experiments should be considered in further study of NSRS in milling, but also when studying NSRS in other contexts (in fact, the wafer experiment is similar to the Almen strip experiments used extensively in engineering and process control for shot peening [24].

The wafer distortion experiments also highlight the value and importance of collecting shear stress data for milling, which often goes ignored in the literature. Figure 18 shows the contribution of normal and shear components of NSRS to the wafer distortion, with calculations using the
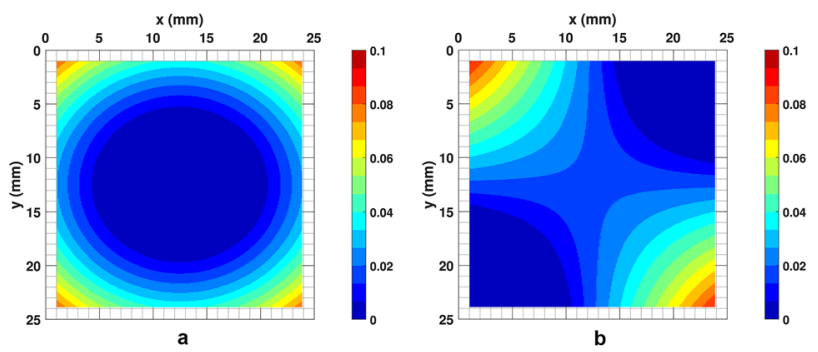

Fig. 18 Effect of shear stress on computed wafer topography for sample B4 using hole-drilling data: a result including only normal stress $\sigma_{\mathrm{xx}}$ and $\sigma_{y y}$, and $\mathbf{b}$ result including only shear stress $\sigma_{x y}$ (color scale in $\mathrm{mm}$ )

hole-drilling data of Fig. 12. The calculated distortion due to normal components of NSRS (Fig. 18a) shows a bowlshaped convex machined surface with peak displacements of 0.06 to $0.08 \mathrm{~mm}$ at the corners. The calculated distortion due to shear NSRS (Fig. 18b) shows a saddle shape with peak displacements of 0.05 to $0.08 \mathrm{~mm}$ occurring at the corners $(0,0)$ and $(25,25) \mathrm{mm}$. The sum of these contributions produces the elliptical shape of Fig. 13b with principal curvatures rotated from the orthogonal machining axes. Without the shear stress data, it would be impossible to correlate the observed distortion.

\section{Technique Advantages/Disadvantages}

Each of the techniques used here has particular attributes that may make it useful in application. The hole-drilling technique provides three components of stress per measurement and, based on this work, produces measured stresses that correlate best with observed distortion. The data (Fig. 7 and Fig. 8) show hole-drilling offers the best repeatability at depths $>0.03 \mathrm{~mm}$ with standard deviation less than $20 \mathrm{MPa}$. The hole-drilling technique has some dispersion at shallow depths $(<0.03 \mathrm{~mm})$, near the machined surface where the standard deviation climbs to around $40 \mathrm{MPa}$, but this is perhaps exacerbated in the present conditions by significant surface topography. From a practical perspective, the bespoke automated apparatus used for hole-drilling was useful in ensuring good quality experiments.

The slotting technique provides one stress component per measurement. Different stress components can be measured by changing slot orientation but assessing an arbitrary planar stress state would require three separate measurements. The data (Fig. 7) show slotting offers good near surface repeatability at depths $<0.03 \mathrm{~mm}$ with standard deviations of 20 to $35 \mathrm{MPa}$. For depths $>0.03 \mathrm{~mm}$ the slotting data closely match the hole-drilling data.

The $\cos (\alpha)$ XRD technique did not work as well as the others in these conditions. The average depth profile (Fig. 7 and Fig. 8) has the same general trend as other techniques 
but the data exhibit significantly larger standard deviation that fluctuates with depth.

The $\sin ^{2}(\psi)$ XRD technique offers three stress components and provided data that agree well with data from slotting and hole-drilling. The data (Fig. 7 and Fig. 8) show good repeatability at shallow depths $(<0.03 \mathrm{~mm})$ with standard deviation $<20 \mathrm{MPa}$. At moderate and larger depths $(>0.03 \mathrm{~mm})$ $\sin ^{2}(\psi)$ XRD was less repeatable with standard deviation rising to $40 \mathrm{MPa}$. Data from the $\sin ^{2}(\psi) \mathrm{XRD}$ technique provided reasonable correlation of observed wafer distortion.

Overall, the mechanical and diffraction techniques used in this work are applicable for measuring NSRS, with the hole-drilling technique providing more consistent results in the present conditions. It is important to note that successful application of any of these residual stress measurement techniques requires sound procedures, meaningful operator training, and, for every test, careful setup and execution.

\section{Conclusion}

The measurement of near surface residual stress (NSRS) in milled aluminum samples has been considered through the above study. Major conclusions are:

- Average depth profiles from multiple measurements by hole-drilling, slotting, and $\sin ^{2}(\psi) x$-ray diffraction (XRD) techniques were largely consistent with one another; the $\cos (\alpha)$ XRD technique did not produce comparable results in several conditions.

- The hole-drilling and slotting techniques had better repeatability than XRD techniques at depths greater than $0.05 \mathrm{~mm}$; the opposite was true at depths shallower than $0.05 \mathrm{~mm}$.

- Milling with increased feed per tooth produced a deeper layer of NSRS.

- Milling with different cutting speeds at fixed feed per tooth did not significantly affect NSRS.

- A simple wafer distortion experiment was useful in validating the measured NSRS data:

○ Observed wafer distortion was correlated closely by hole-drilling data and reasonably by $\sin ^{2}(\psi)$ XRD data.

- Wafer curvature principal directions were rotated relative to the milling direction, which highlighted the importance of measuring the shear component of NSRS.

The evaluation of the effects of different machining parameters on NSRS reported here is preliminary, and the amount of data are limited. Follow on work by the authors is using repeated measurements in replicate samples to complete this evaluation.
Acknowledgements The authors would like to thank Toshikazu Suzuki, of Pulstec (Torrance, CA USA), for the loan of the $\mu$-X360s $\mathrm{X}$-Ray residual stress measurement system and associated training. Thank you to Hill Engineering, LLC (Rancho Cordova, CA USA) for the loan and training on their NSRS measurement device. Deutsche Forschungsgemeinshaft (DFG) provided financial support within project AU 185/64-1 to TUK. UC Davis received funding from the National Science Foundation under Award No. 1663341 (Division of Civil, Mechanical and Manufacturing Innovation (CMMI)). Any opinions, findings, and conclusions or recommendations expressed in this material are those of the authors and do not necessarily reflect the views of the National Science Foundation.

\section{Declarations}

Conflicts of Interest This study was performed by the authors with the support noted above. All authors report no potential conflicts of interest that played a significant role in this work.

Open Access This article is licensed under a Creative Commons Attribution 4.0 International License, which permits use, sharing, adaptation, distribution and reproduction in any medium or format, as long as you give appropriate credit to the original author(s) and the source, provide a link to the Creative Commons licence, and indicate if changes were made. The images or other third party material in this article are included in the article's Creative Commons licence, unless indicated otherwise in a credit line to the material. If material is not included in the article's Creative Commons licence and your intended use is not permitted by statutory regulation or exceeds the permitted use, you will need to obtain permission directly from the copyright holder. To view a copy of this licence, visit http://creativecommons.org/licenses/by/4.0/.

\section{References}

1. Chantzis D, Van-der-Veen S, Zettler J, Sim WM (2013) An industrial workflow to minimize part distortion for machining of large monolithic components in aerospace industry. Procedia CIRP 8:281-286. https://doi.org/10.1016/j.procir.2013.06.103

2. Sim W (2010) Challenges of residual stress and part distortion in the civil airframe industry. Int J Microstruct Mater Prop 5(45):446-455. https://doi.org/10.1504/IJMMP.2010.037621

3. Madariaga A et al (2018) Reduction of distortions in large aluminum parts by controlling machining-induced residual stresses. Int J Adv Manuf Tech 97:967-978. https://doi.org/10.1007/ s00170-018-1965-2

4. Masoudi S, Saeid A, Ehsan S, Hamdollah E (2015) Effect of machining-induced residual stress on the distortion of thin-walled parts. Int J Adv Manuf Tech 76(1):597-608. https://doi.org/10. 1007/s00170-014-6281-x

5. Li B, Jiang X, Yang J, Liang S (2015) Effects of depth of cut on the redistribution of residual stress and distortion during the milling of thin-walled part. J Mater Process Technol 216:223-233. https://doi.org/10.1016/J.JMATPROTEC.2014.09.016

6. Grant P (2002) Evaluation of the repeatability of residual stress measurements using X-Ray diffraction. NPL Report MATC(MN)20

7. Hill M, Olson M (2014) Repeatability of the contour method for residual stress measurement. Exp Mech 54:1269-1277. https:// doi.org/10.1007/s11340-014-9867-1 
8. Lee MJ, Hill MR (2007) Intralaboratory repeatability of residual stress determined by the slitting method. Exp Mech 47:745. https://doi.org/10.1007/s11340-007-9085-1

9. Li J, Shu-qi W (2016) Distortion caused by residual stresses in machining aeronautical aluminum alloy parts: recent advances. Int J Adv Manuf Tech 89:997-1012. https://doi.org/10.1007/ s00170-016-9066-6

10. Denkena B, de Leon L (2008) Milling induced residual stresses in structural parts out of forged aluminium alloys. Int J Machining Machinability Mater 4(4). https://doi.org/10.1504/IJMMM.2008. 023717

11. Denkena B, Boehnke D, de Leon L (2008) Machining induced residual stress in structural aluminum parts. Prod Eng Res Devel 2:247-253. https://doi.org/10.1007/s11740-008-0097-1

12. Rao B, Shin Y (2001) Analysis on high-speed face-milling of 7075-T6 aluminum using carbide and diamond cutters. Int J Mach Tools Manuf 41:1763-1781. https://doi.org/10.1016/S08906955(01)00033-5

13. Tang ZT, Liu ZQ, Wan Y, Ai X (2008) Study on residual stresses in milling aluminium alloy 7050-T7451. In: Yan XT., Jiang C., Eynard B. (eds) Advanced Design and Manufacture to Gain a Competitive Edge. Springer, London. https://doi.org/10.1007/9781-84800-241-8_18

14. Ma Y, Feng P, Zhang J, Wu Z, Yu D (2016) Prediction of surface residual stress after end milling based on cutting force and temperature. J Mater Process Technol 235:41-48. https://doi.org/10. 1016/j.jmatprotec.2016.04.002

15. Toenshoff HK, Denkena B (2013) Basics of cutting and abrasive processes. Springer Science \& Business Media

16. Grant P, Lord J, Whitehead P, Fry AT (2006) The application of fine increment hole drilling for measuring machining-induced residual stresses. Appl Mech Mater 3-4:105-110. https://doi.org/ 10.4028/www.scientific.net/AMM.3-4.105

17. ASTM International (2013) E837-13a standard test method for determining residual stresses by the hole-drilling strain-gage method. West Conshohocken, PA: ASTM International. https:// doi.org/10.1520/E0837-13A

18. Schajer GS, Whitehead PS (2017) Hole-drilling method for measuring residual stresses. Synthesis SEM lectures on experimental mechanicas. Morgan \& Claypool Publishers. pp. 30-32. https:// doi.org/10.2200/S00818ED1V01Y201712SEM001

19. Tanaka K (2017) The cosine alpha method for X-ray residual stress measurement using two-dimensional detector. The Japan Society of Mechanical Engineers 66(7):470-478. https://doi.org/ $10.2472 /$ jsms. 66.470

20. German Institute for Standardisation (2009) DIN EN 15305:2009 Non-destructive testing- test method for residual stress analysis by X-ray diffraction. Test Stand DIN

21. Eigenmann B, Macherauch E (1995) Röntgenographische untersuchung von spannungszuständen in werkstoffen. Materialwissenshaft und Werkstofftechnik 26:148-160. https://doi.org/10.1002/ mawe. 19950260310

22. Macherauch E, Müller P (1961) Das $\sin ^{2}$ Psi-Verfahren der röntgenographischen Spannungsmessung. Zeitschrift für angewandte Physik. 305-312

23. Lee S, Ling J, Wang S, Ramirez-Rico J (2017) Precision and accuracy of stress measurement with a portable X-ray machine using an area detector. J Appl Crystallogr 50:131-144. https://doi.org/ $10.1107 / \mathrm{S} 1600576716018914$

24. Almen JO, Black PH (1963) Residual stresses and fatigue in metals. McGraw-Hill

Publisher's Note Springer Nature remains neutral with regard to jurisdictional claims in published maps and institutional affiliations. 